\title{
Departamento de Formación y Actualización Académica
}

Jesús Martínez Ruiz Velasco

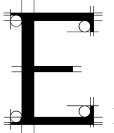

$\mathrm{n}$ el marco del proceso de reestructura organizativa de algunas áreas de apoyo de la Universidad Autónoma de Aguascalientes, a partir de febrero de 2011, la Coordinación de la Unidad de Formación Académica de Profesores (UFAP) se transformó en el Departamento de Formación y Actualización Académica (DEFAA).

Dicha área tiene como misión: facilitar en los profesores de la Universidad Autónoma de Aguascalientes y de Instituciones de Educación Media Superior y Superior externas, una formación y actualización docente a través de un conjunto integrado de servicios educativos diversificados y flexibles que coadyuvan en desarrollar una docencia renovada y de calidad, acorde con los planteamientos de los Modelos Educativo y Curricular, así como a las tendencias de la Educación Media Superior y Superior.

En tanto que en su visión de futuro se plantea que el DEFAA es el área líder a nivel estatal en materia de formación y actualización docente, tiene un reconocimiento regional y nacional en algunos de los servicios educativos que ofrece, como es el caso de un Programa de Formación y Actualización Académica de Profesores diversificado y flexible, asesorías pedagógicas, medios de difusión variados y otros proyectos académicos, todos los cuales se encuentran plenamente vinculados e integrados entre sí. De esta manera, el DEFAA coadyuva en facilitar la formación y actualización docente en los profesores de la Universidad Autónoma de Aguascalientes y de otras Instituciones de Educación Media Superior y Superior.

Para avanzar en el logro de esta visión, actualmente se ofrecen los siguientes servicios educativos:

Oferta educativa: cursos y talleres presenciales, semipresenciales y en línea, sobre los siguientes ejes temáticos: identidad institucional, diseño curricular, metodologías de enseñanza centradas en el aprendizaje, tecnologías de la información y comunicación aplicadas a la educación, evaluación alternativa de los aprendizajes, formación humanista en el profesor, tutoría y lenguas extranjeras. Además de la oferta general de cursos, se atienden peticiones especiales de 
formación y actualización docente provenientes de profesores, Academias, Departamentos y Centros Académicos de la UAA, así como de otras Instituciones de Educación Media Superior y Superior.

Asesoría pedagógica: espacio de atención individual y grupal a través del cual se pretende ofrecer al profesor orientaciones relativas a la planeación, ejecución, seguimiento y evaluación de procesos educativos vinculados con la práctica docente.

Medios de difusión: integra diversos medios de distinto tipo que tienen como propósito en común divulgar de forma interna y externa a la UAA, información relevante vinculada con la educación en general y la práctica docente en particular, así como con el ser y hacer del DEFAA, todo ello para coadyuvar en la formación y actualización docente de los profesores.

Actualmente, los medios de difusión con que cuenta el DEFAA son: revista semestral Docere, página web, programa de radio El Gis (se transmite los jueves a las 14:00 hrs. a través de Radio Universidad), "Redocente" (correo electrónico) y colaboraciones para Gaceta UAA.

Proyectos académicos especiales: se encamina a detectar, analizar e integrar necesidades vinculadas a la formación y actualización docente de los profesores que puedan ser atendidas a través de la formulación de proyectos académicos especiales, sean éstos de carácter interno (DEFAA), institucionales, en colaboración con otras áreas de la UAA, o incluso, interinstitucionales.

Con gusto le atenderemos en la planta baja del Edificio de la Unidad de Estudios Avanzados, tel. 910-74-00, ext. 205, así como a través del correo electrónico formaprofe@correo.uaa.mx y en la página web http://ufap.dgdp.uaa.mx

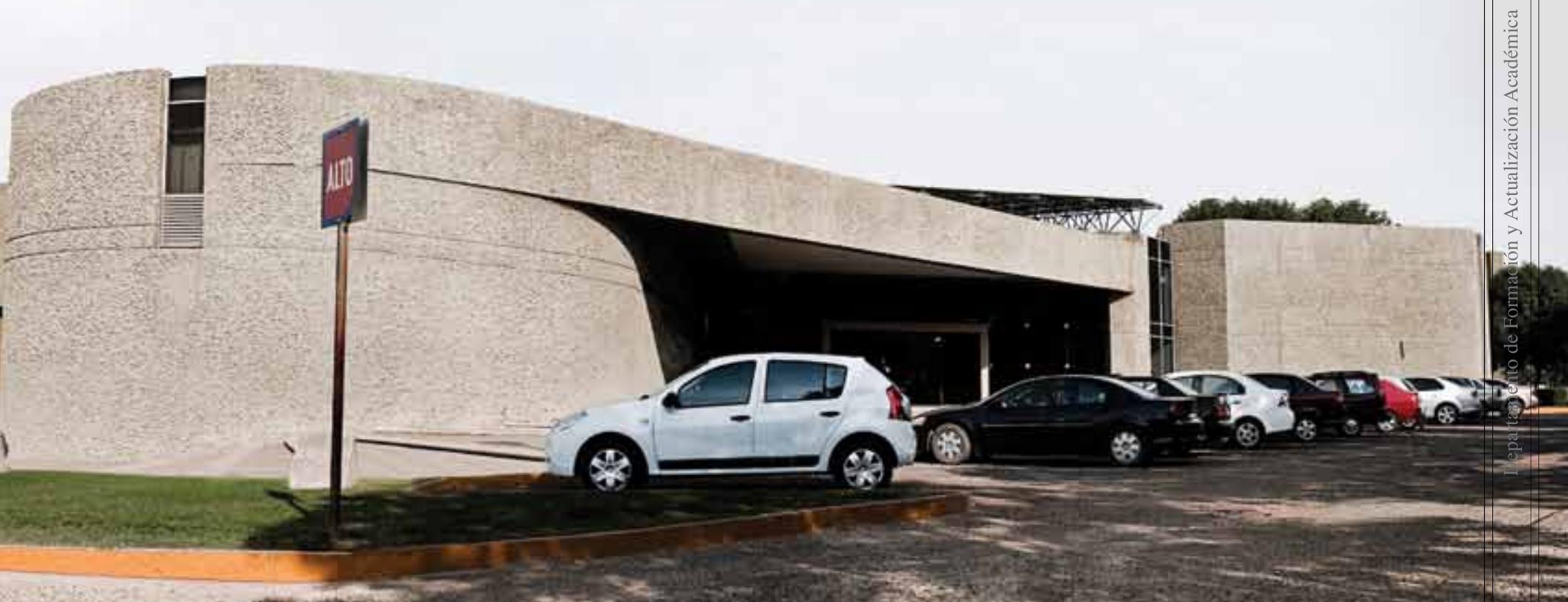

